\title{
Prolonged External Ventricular Drainage to Treat Cryptococcus Gattii-Induced Intracranial Hypertension without Hydrocephalus.
}

\author{
Ameya Kamat ${ }^{1}$, Kelvin Woon ${ }^{2}$ \\ 1. Medical Officer, Groote Schuur Hospital 2. Department of Neurosurgery, Wellington Regional Hospital
}

$\square$ Corresponding author: Ameya Kamat, amskam@gmail.com

Disclosures can be found in Additional Information at the end of the article

\section{Abstract}

The use of prolonged external ventricular drainage to treat uncontrollable intracranial hypertension in patients with cerebral cryptococcomas without hydrocephalus is unique and remains largely unreported. This condition, however, can be life-threatening. Early diagnosis and cerebrospinal fluid diversion techniques are important and are essential to survival and neurological function. We report a case of uncontrollable intracranial hypertension without hydrocephalus in a 21-year-old man which was successfully managed by prolonged external ventricular drainage.

Categories: Neurosurgery

Keywords: cryptococcus gattii, uncontrolled intracranial hypertension, external ventricular drain

\section{Introduction}

The increasing incidence of cryptococcal meningitis associated with immunocompromised patients is well-documented, especially since the onset of the AIDS epidemic. However, several immunocompetent patients develop the illness together with cerebral cryptococcomas. Elevated intracranial pressure is a common complication found in both HIV-negative and HIVpositive patients. The use of prolonged external ventricular drainage to treat uncontrollable intracranial hypertension in patients with cerebral cryptococcomas without hydrocephalus is unique and remains largely unreported. This condition, however, can be life-threatening. We report a case of uncontrollable intracranial hypertension without hydrocephalus in a 21-yearold man which was successfully managed by prolonged external ventricular drainage.

Received 02/03/2013 Review began 02/03/2013 Published 02/03/2013

\section{() Copyright 2013}

Kamat et al. This is an open access article distributed under the terms of the Creative Commons Attribution License CC-BY 3.0., which permits unrestricted use, distribution, and reproduction in any medium, provided the original author and source are credited.

\section{Case Presentation}

A 21-year-old immunocompetent man presented to our hospital via the Emergency Department complaining of a five week history of global headaches, a two week history of nausea, vomiting and fevers, and an $11 \mathrm{~kg}$ weight loss over a three week period. The headaches were preceded by an aura. He had no other significant past medical history with the exception of mild asthma. He was a non-smoker. On further questioning, however, the patient did state that he spent four weeks in Queensland, Australia, climbing Eucalyptus trees as a past-time.

Examination findings demonstrated a well-looking man with a Glasgow Coma Scale (GCS) of $15 / 15$. The cranial nerve, cerebellar and sensory examinations were unremarkable. Motor exam revealed decreased power (Grade 4/5) in all muscle groups of his right upper limb. The rest of 


\section{Cureus}

his motor and systemic exam was unremarkable.

Serology tests for Human Immunodeficiency Virus (HIV) and Hepatitis B and C were negative. The white cell count and C-reactive protein tests were within normal limits.

The chest X-ray revealed a patchy opacity medial to left lung base posterior to the heart. Computerized tomography (CT) of the patient's head displayed multiple enhancing lesions in the brain, initially thought to be metastases (Figure 1).
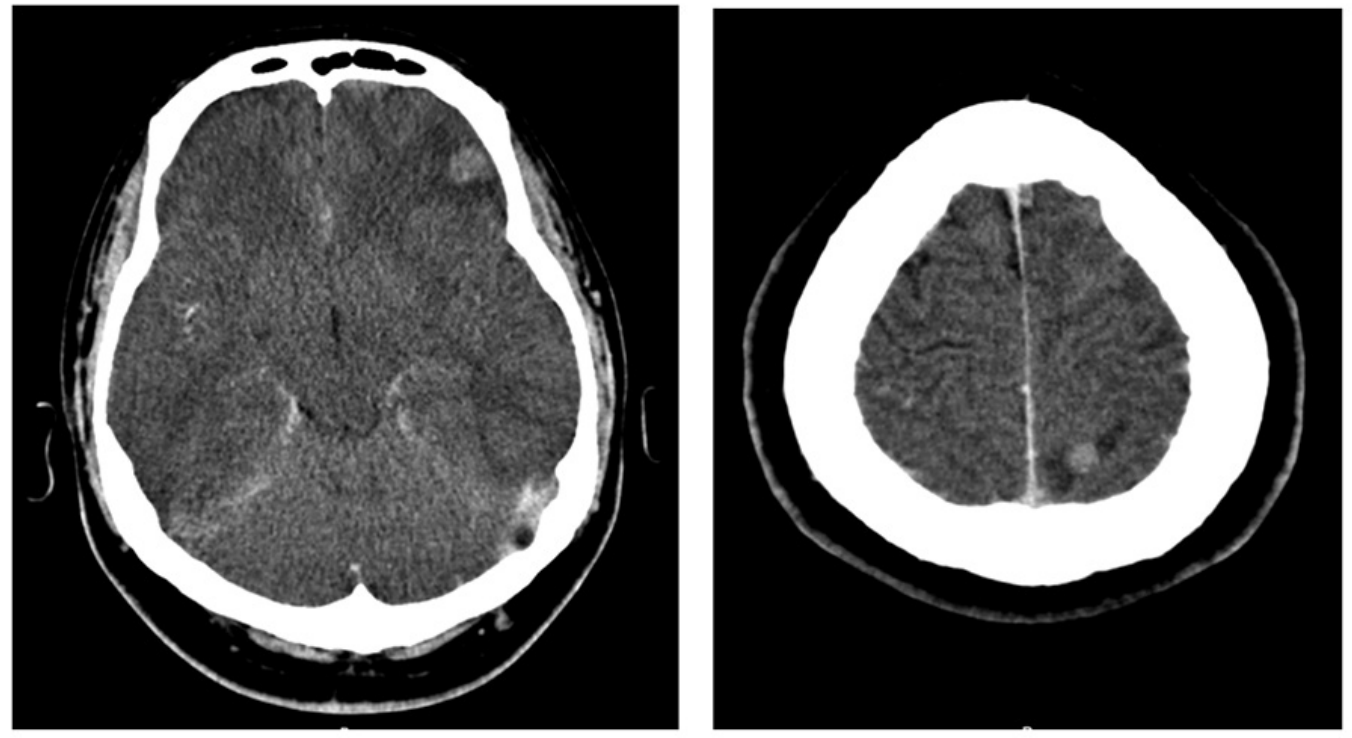

\section{FIGURE 1: Axial contrast-enhanced computerized tomography}

Axial contrast-enhanced computerized tomography demonstrating multiple ring enhancing space occupying lesions within the cerebral hemispheres with surrounding vasogenic edema.

As part of his work up, a CT-guided biopsy of the pulmonary lesion was performed. This demonstrated the presence of Cryptococcus gattii. Magnetic resonance imaging (MRI) of the brain was then performed with and without contrast. This demonstrated multiple cerebral lesions with surrounding oedema and lack of enhancement, thus in keeping with cryptococcomas (Figure 2). Subsequently, a lumbar puncture was performed under fluoroscopy which demonstrated an opening pressure of $25 \mathrm{~cm}$ of H2O, and cerebrospinal fluid (CSF) specimens confirmed the presence of Cryptococcus gattii. 


\section{Cureus}

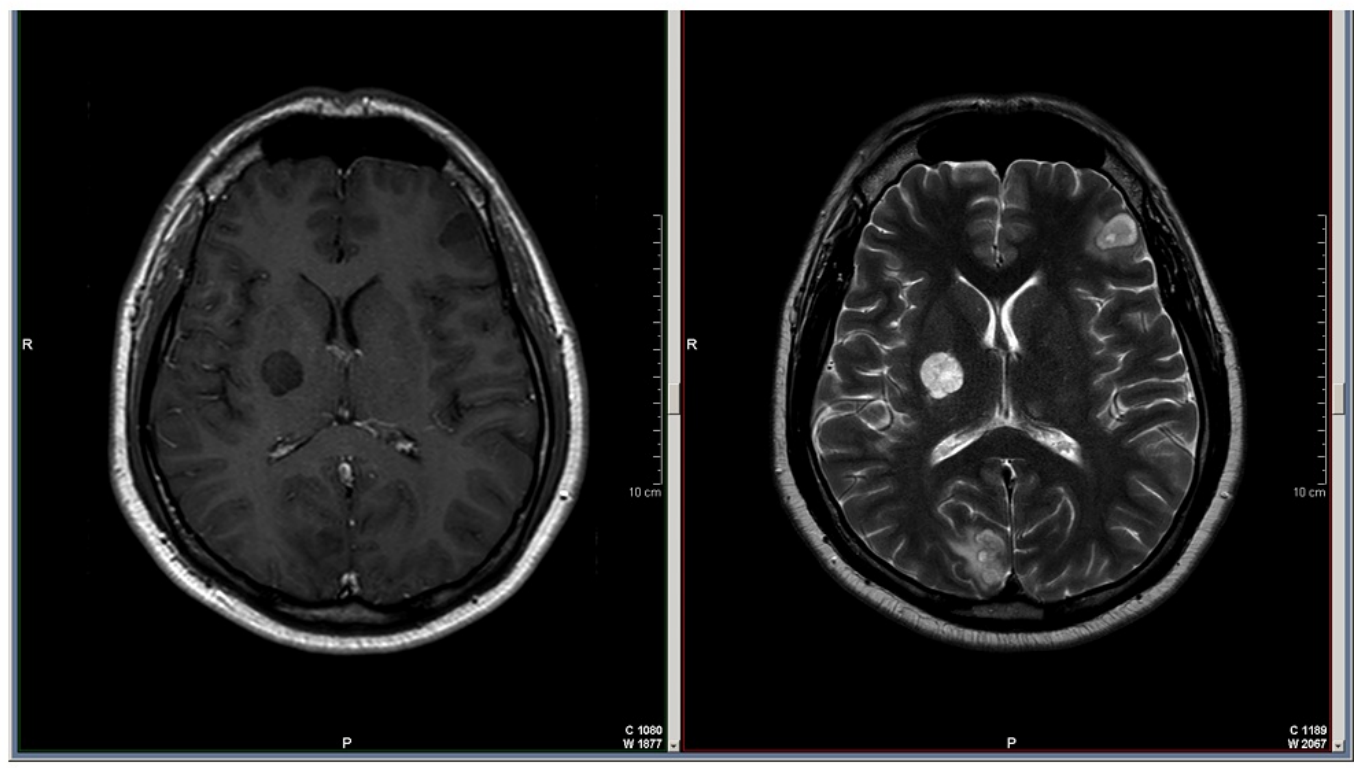

FIGURE 2: Axial T1 post-gadolinium (A) and axial T2 (B) MRI

Axial T1 post-gadolinium (A) and axial T2 (B) MRI demonstrating multiple non-enhancing lesions in keeping with cerebral cryptococcomas.

The patient was initially treated with Amphotericin B and Dexamethasone. His symptoms resolved three weeks later, and his CSF was clear. He was then placed on Fluconazole and 5flucytosine and treated in the outpatient setting.

Four weeks after discharge, the patient returned to the emergency department with an encephalopathy. His CT scan demonstrated collapsed ventricles and resolving cryptococcomas. A lumbar puncture (LP) was subsequently performed which revealed an opening pressure of 55 $\mathrm{cm}$ of H2O. Forty $\mathrm{ml}$ of CSF was drained and the closing pressure was $16 \mathrm{~cm}$ of H2O. His CSF samples were unremarkable with the exception of a grossly elevated protein content. The patient's symptoms improved after lumbar puncture but recurred 48 hours later requiring serial LP's which demonstrated raised intracranial pressure (ICP). He was commenced of Acetazolamide orally. His visual acuity was also noted to be significantly diminished and papilloedema was evident on fundoscopy.

Approximately seven weeks after initial presentation, a decision was made to insert a ventriculoperitoneal shunt. Postoperatively he was well with no headaches and a GCS of 15 . Three days later, however, his headaches had returned and he had a sustained decrease in his conscious state. His repeat CT head was unchanged. His shunt reservoir was aspirated and this revealed S. aureus infection. The shunt was subsequently removed and the ventricular catheter was deemed blocked intraoperatively. An antibiotic coated external ventricular drain (EVD) was placed into his right frontal horn. Postoperatively, the patient was well with no neurological deficit. The patient's condition improved significantly after EVD insertion. His vision had returned to normal, and he was pain-free with a GCS of 15. The EVD was retained for 21 days and subsequently clamped for 72 hours prior to it being removed. After EVD removal, the patient had returned to his pre-morbid baseline and his ventricular size appeared normal on CT scan.

\section{Discussion}


The increasing incidence of cryptococcal meningitis associated with immunocompromised patients is well-documented, especially since the onset of the AIDS epidemic [1]. However, several immunocompetent patients develop the illness together with cerebral cryptococcomas. Elevated intracranial pressure is a common complication found in both HIV-negative and HIVpositive patients. The frequency of raised intracranial pressure is reported differently in the literature. In an observational study, 30\% had an intracranial pressure $135 \mathrm{~cm}$ of $\mathrm{H} 2 \mathrm{O}$ and $60 \%$ of the patients had an intracranial pressure $125 \mathrm{~cm}$ of $\mathrm{H} 2 \mathrm{O}$ [1].

Numerous mechanisms have been implicated in the development of raised intracranial pressure (ICP) in association with cryptococcal infection. It has been deduced that infection may cause an obstruction in CSF outflow by blocking the passage of fluid across the arachnoid villi or fungal polysaccharides may aggregate and accumulate in the arachnoid villi and subarachnoid spaces, hence blocking channels for CSF drainage [1-3]. However, ventriculomegaly does not present in the majority of patients. This is the case with our patient. The mechanism for this is not well understood, but some authors suggest that capsular cryptococcal polysaccharides in the brain parenchyma lead to the ventricles being unable compensate for the increase in the volume of CSF [4-6]. This may be explained by failure of the ventricles to compensate for increased pressure on the brain, accompanied by a loss of compliance.

Raised ICP could develop, causing a progressive neurological deficit, and thereby increasing the mortality and morbidity associated with cerebral cryptococcomas [1, 3, 7].

The most common manifestations of raised ICP in patients with cerebral cryptococcal infection may include severe headache, decreased consciousness, papilloedema, visual abnormalities, and hearing loss [7]. High ICP can lead to impaired cerebral circulation, which may cause a loss of visual acuity and may be associated with significant morbidity and mortality. Loss of vision also may be secondary to direct invasion of the optic nerve by the fungus species or secondary to an immune-mediated response [3, 8]. A raised ICP can occur at anytime during the course of the infection, including the treatment phase [1]. This seemed to be the case with our patient.

Frequent lumbar punctures and measurements of ICP are essential for the survival of patients.

Aggressive management of raised ICP is the most important factor in reducing morbidity and mortality in patients with cerebral cryptococcomas $[7,9]$.

Several treatment options for managing raised ICP have been described. These include administration of dexamethasone and acetazolamide [10-11]. Serial lumbar punctures, CSF diversion techniques (ventriculoperitoneal (VP) and lumbar-peritoneal (LP) shunting and insertion of a lumbar drains) [12].

The optimal management of cryptococcal disease resulting in raised ICP without hydrocephalus is debatable. VP shunts have been described in patients with cryptococcal meningitis with some success [13]. However, our experience suggests that these shunts are more prone to failure in patients with raised intracranial pressure [5].

We believe prolonged antibiotic-coated external ventricular drainage (EVD) is the optimum technique due to the presumed increase in risk of shunt infection due to active infection, shunt obstruction from elevated CSF protein (the case in our patient), and the risk of peritoneal Cryptococcus seeding from direct dissemination of infected fluid.

Uncontrollable intracranial pressure without hydrocephalus in patients with cryptococcal infection is a potentially fatal condition. The situation for such patients is usually complicated, 
hence management of this condition can be very difficult [14]. Although no definite guidelines exist for treating these patients, early diagnosis and early use of CSF diversion surgery (which might include prolonged EVD usage) to remove not only the large amount of fluid but also fungal polysaccharides is essential to the survival. The main advantage of an EVD would be the fact that they could easily be re-inserted if blocked. VP shunt revisions are more onerous with increased risk of complications with regards to revision, especially if shunts continue to get blocked secondary to high CSF protein content. Another significant advantage of prolonged EVD usage is that no permanent remnants are retained in situ.

To our knowledge, prolonged external ventricular drainage has not been previously documented as a treatment option in patients with cryptococcal infection.

\section{Conclusions}

N/A

\section{Additional Information}

\section{Disclosures}

Human subjects: Consent was obtained by all participants in this study. Conflicts of interest: In compliance with the ICMJE uniform disclosure form, all authors declare the following:

Payment/services info: All authors have declared that no financial support was received from any organization for the submitted work. Financial relationships: All authors have declared that they have no financial relationships at present or within the previous three years with any organizations that might have an interest in the submitted work. Other relationships: All authors have declared that there are no other relationships or activities that could appear to have influenced the submitted work.

\section{References}

1. Denning DW, Armstrong RW, Lewis BH, Stevens DA: Elevated cerebrospinal fluid pressure in patients with cryptococcal meningitis and acquired immunodeficiency syndrome. Am J Med. 1991, 91:267-72. 10.1016/0002-9343(91)90126-I

2. Stevens DA, Denning DW, Shatsky S, Armstrong RW, Adler JD, Lewis BH: Cryptococcal meningitis in the immunocompromised host: intracranial hypertension and other complications. Mycopathologia . 1999, 146:1-8.

3. Tang LM: Ventriculoperitoneal shunt in cryptococcal meningitis with hydrocephalus. Surg Neurol. 1990, 33:314-9. 10.1016/0090-3019(90)90198-X

4. Bach MC, Tally PW, Godofsky EW: Use of cerebrospinal fluid shunts in patients having acquired immunodeficiency syndrome with cryptococcal meningitis and uncontrollable intracranial hypertension. Neurosurgery. 1997, 41:1280-3. 10.1097/00006123-19971200000008

5. Lee SC, Casadevall A, Dickson DW: Immunohistochemical localization of capsular polysaccharide antigen in the central nervous system cells in cryptococcal meningoencephalitis. Am J Pathol. 1996, 148:1267-74.

6. Lee SC, Casadevall A: Polysaccharide antigen in brain tissue of AIDS patients with cryptococcal meningitis. Clin Infect Dis. 1996, 23:194-5. 10.1093/clinids/23.1.194

7. Saag MS, Graybill RJ, Larsen RA, et al: Practice guidelines for the management of cryptococcal disease. Clin Infect Dis. 2000, 30:710-8. 10.1086/313757

8. Seaton RA, Verma N, Naraqi S, Wembri JP, Warrell DA: Visual loss in immunocompetent patients with Cryptococcus neoformans var gattii meningitis. Trans R Soc Trop Med Hyg. 1997, 91:44-9. 10.1016/S0035-9203(97)90391-6

9. Denning DW, Armstrong RW, Lewis BH, Stevens DA: Elevated cerebrospinal fluid pressure in patients with cryptococcal meningitis and acquired immunodeficiency syndrome. Am J Med. 1991, 91:267-72. 10.1016/0002-9343(91)90126-I 


\section{Cureus}

10. Johnston SR, Corbett EL, Foster O, Ash S, Cohen J: Raised intracranial pressure and visual complications in AIDS patients with cryptococcal meningitis. J Infect. 1992, 24:185-9. 10.1016/0163-4453(92)92954-H

11. Laverda AM, Ruga E, Pagliaro A, Pinello ML, Giaquinto C: Intracranial hypertension and cryptococcal meningitis in a girl with AIDS. Brain Dev. 1996, 18:330-1. 10.1016/03877604(96)00022-8

12. Fessler RD, Sobel J, Guyot L, et al: Management of elevated intracranial pressure in patients with cryptococcal meningitis. J Acquir Immune Defic Syndr Hum Retrovirol. 1998, 17:137-42. 10.1097/00042560-199802010-00006

13. Bach MC, Tally PW, Godofsky EW: Use of cerebrospinal fluid shunts in patients having acquired immunodeficiency syndrome with cryptococcal meningitis and uncontrollable intracranial hypertension. Neurosurgery. 1997, 41:1280- 3. 10.1097/00006123-19971200000008

14. Liliang PC, Liang CL, Chang WN, Lu K, Lu CH: Use of ventriculoperitoneal shunts to treat uncontrollable intracranial hypertension in patients who have cryptococcal meningitis without hydrocephalus. Clin Infect Dis. 2002, 34:64-68. 10.1086/340525 